DEMOCRATIZATION OF INSTITUTION OF POLITICAL PARTIES IN INDONESIA THROUGH MANAGEMENT OF MODERN POLITICAL PARTIES: THEORETICAL REVIEW AND REGULATION

\title{
DEMOKRATISASI KELEMBAGAAN PARTAI POLITIK DI INDONESIA MELALUI MANAJEMEN PARTAI POLITIK MODERN: TINJAUAN TEORITIS DAN REGULASI
}

\author{
Rudi Salam Sinaga ${ }^{1}$, Fadli Arief Hasibuan ${ }^{2}$, Arohman Putra Sinaga ${ }^{3}$, Firman Gea ${ }^{4}$, \\ Meliserius Zega ${ }^{5}$ \\ ${ }^{1}$ Jl. Kolam No 1 Medan Estate. FISIPOL Universitas Medan Area. \\ ${ }^{2}$ Jl. Dahlia No. 5 Kelurahan Pahlawan Binjai. Kota Binjai. \\ ${ }^{3}$ Jl. Dusun X RSTS Desa Tebing Tanjung Selamat. PD Tualang. Kabupaten Langkat. \\ ${ }^{4}$ Jl. Rajawali I No. 14. Percut Sei Tuan Kota Medan. \\ ${ }^{5}$ Jl. Jl. Huno. Desa Umbubalodano. Kecamatan Sitolu Ori. Kabupaten Nias Utara. \\ Email: rudisalam@staff.uma.ac.id
}

\begin{abstract}
This study aims to find out the concept of modern political party management in the theoretical context and examine the availability of the conceptual indicator in the regulatory level that regulates the political party in Indonesia in the framework of the theory of democratization of political parties. This study uses a qualitative approach with grounded theory type. Methods of data collection using literature study and documentation. Data and information obtained from the relevant literature of books mainly derived from the concept of modern political party management proposed Hofmeister and Grabow (2011) and the study of the Law applicable in Indonesia on Political Parties. The results of this study find indicators of the modern management concept of political parties Hofmeister and Grabow (2011) are in line with the principles contained in Law No. 2 of 2011 on amendments to Law No. 2 of 2008 on Political Parties. The perfection of the implementation of the management of modern political parties to achieve a democratic political party in every process within the party depends on the will of the political party itself.
\end{abstract}

Keywords: Democratization, Political Party, Modern, Political Party Management.

\begin{abstract}
Abstrak
Studi ini bertujuan untuk mengetahui konsep manajemen partai politik modern pada konteks teoritis dan menelaah ketersediaan indikator konsep tersebut dalam tataran regulasi yang mengatur mengenai partai politik di Indonesia dalam bingkai teori demokratisasi partai politik. Studi ini menggunakan pendekatan kualitatif dengan jenis grounded theory. Metode pengumpulan data menggunakan studi pustaka dan dokumentasi. Data dan informasi didapatkan dari literatur buku yang relevan terutama bersumber dari konsep manajemen partai politik modern yang dikemukakan Hofmeister dan Grabow (2011) dan telaah Undang-Undang yang berlaku di Indonesia tentang Partai Politik. Hasil dari studi ini mendapatkan indikator-indikator dari konsep manajemen partai politik modern Hofmeister dan Grabow (2011) telah sejalan dengan prinsip-prinsip yang termuat di dalam Undang-Undang nomor 2 tahun 2011 tentang perubahan atas Undang-Undang nomor 2 tahun 2008 tentang Partai Politik. Kesempurnaan terhadap implementasi manajemen partai politik modern untuk mencapai partai politik yang demokratis dalam setiap proses di internal partai bergantung pada kemauan dari partai politik itu sendiri.
\end{abstract}

Kata kunci: Demokratisasi, Partai Politik, Modern, Manajemen Partai Politik. 


\section{PENDAHULUAN}

Fenomena lemahnya kelembagaan partai politik di Indonesia telah menjadi perhatian serius bagi ilmuwan politik di tanah air. Potret kelembagaan partai yang "dekat" dengan masalah pelanggaran hukum seperti kasus suap-menyuap, korupsi, penyalahgunaan narkoba, konflik kekuasaan di internal partai, eksklusifitas partai, lemahnya fungsi partai serta janji politik di pemilu yang tidak kunjung terealisasi berimplikasi menurunya simpatik publik terhadap partai politik. Penurunan simpatik publik terhadap partai politik tercermin dalam sejumlah temuan hasil survei yang dilakukan oleh sejumlah lembaga survei terpercaya seperti Skala Survei Indonesia (SSI) tahun 2011, Lembaga Survei Cirus Surveyors Group tahun 2013, Saiful Mujani Research and Consulting (SMRC) tahun 2015, dan Lembaga Survei Indonesia (2016) yang dari keseluruhan hasil survei lembagalembaga ini menyimpulkan terjadinya penurunan kepercayaan publik terhadap partai politik sejak tahun 2001 hingga 2016.

Implikasi menurunnya simpatik publik terhadap partai politik tentu berdampak pada kerelaan publik untuk memberikan hak pilih dalam pemilu, asumsi ini sejalan dengan data The International Institute for Democracy and Electoral Assistance (International IDEA) yang menjelaskan adanya penurunan partisipasi pemilih dalam menggunakan hak pemilih di pemilu legislatif tahun 1999 hingga tahun 2014.

Tabel: Partisipasi pemilih pada pemilu tahun 1999 hingga tahun 2014.

\begin{tabular}{|l|l|l|}
\hline \multirow{2}{*}{$\begin{array}{c}\text { Pem } \\
\text { ilu }\end{array}$} & \multicolumn{2}{|c|}{ Partisipasi Pemilih } \\
\cline { 2 - 3 } & $\begin{array}{l}\text { Mem } \\
\text { ilih }\end{array}$ & $\begin{array}{l}\text { Tidak } \\
\text { Memilih }\end{array}$ \\
\hline 199 & 93.30 & $6.7 \%$ \\
9 & $\%$ & $15.91 \%$ \\
\hline 200 & 84.09 & \\
4 & $\%$ & $29.01 \%$ \\
\hline 200 & 70.99 & $24.89 \%$ \\
9 & $\%$ & \\
\hline 201 & 75.11 & $\%$ \\
4 & $\%$ & \\
\hline
\end{tabular}

Sumber: The International Institute for Democracy and Electoral Assistance (International IDEA).

GOVERNANCE/ VOLUME 4/ NOMOR 4/ JUNI 2018
Persoalan di atas tidak luput dari masalah-masalah yang muncul dalam kelembagaan internal partai politik yang cenderung melakukan aktivitas politik di internal tanpa diiringi dengan prinsip demokrasi yang dikenal secara universal seperti keadilan, kesetaraan, dan keterbukaan. Masalah-masalah yang terdapat dalam internal partai politik dalam lingkup nasional seperti sentralisasi keputusan yang oligarki dan bersifat "tertutup" (Haris etal., 2005; Budi, 2013)) dan partai yang bersifat kartel (Slater, 2004). Masalah-masalah yang ditemukan dalam internal partai politik di lingkup nasional tersebut juga ditemukan dalam lingkup lokal seperti oligarki partai dalam pengambilan keputusan (Febriani, 2011; Saputra, 2012) dan hadirnya cara-cara informal dalam penentuan calon legislatif (Rahmadania, 2014). Bila masalah-masalah dalam internal kelambagaan partai politik di tingkat nasional telah meringsek masuk dalam struktur kelembagaan partai politik di tingkat yang paling rendah maka situasi ini akan menyebabkan kemunduran bagi masa depan demokrasi Indonesia yang dapat dijabarkan dalam arti yang lebih luas lagi yaitu kemunduran pembangunan negara.

Berangkat dari fenomena dan data empiris yang telah dijelaskan di atas terdapat hubungan antara lemahnya kelembagaan partai politik terhadap penurunan partisipasi pemilih di Pemilu yang diantaranya disebabkan lemahnya proses politik di internal kelembagaan partai politik menandakan adanya persoalan serius yang penting untuk disikapi oleh partai politik di Indonesia karena berkaitan dengan kelangsungan hidup dari demokrasi di Indonesia. Dengan demikian satu-satunya cara untuk menguatkan kelembagaan partai politik dalam sistem demokrasi Indonesia ialah mendemokratisasikan fungsi partai politik sebagaimana lajimnya diterapkan dalam kebanyakan negara demokrasi modern.

Dalam tataran kajian empiris sejumlah kajian yang lebih awal telah mengangkat tema kajian serupa telah dilakukan di negara lain seperti dengan 
membaca karya (He, 2004) melalui disertasinya berjudul Functions of Political Parties in Modern Democratic Elections yang mengkaji tentang fungsi partai politik di pemilu demokrasi modern. Kemudian disertasi Menes (1997) berjudul Modernization and Political Cleavages in Open Party System:Sources of Medium Run Instability in Non Consolidated Democracies: The Case of Spain. Kajian Webb (2001: 308-321) berjudul "Parties and party systems: Modernisation, regulation and diversity" dengan cakupan kurun waktu penelitian pada tahun 1997 hingga tahun 2000 di Inggris

Sementara itu dalam konteks Indonesia belum dapat ditemukan kajian empiris yang relevan dengan studi ini sehingga dalam pandangan hemat penulis kajian ini menjadi penting untuk diselidiki secara ilmiah dengan mengangkat permasalahan besar penelitian ini yaitu bagaimanakah demokratisasi kelembagaan partai politik di Indonesia melalui manajemen partai politik modern.

\section{KAJIAN TEORI}

\section{Demokratisasi Partai Politik}

Studi ini menggunakan teori demokratisasi partai politik yang dikemukakan oleh (Scarrow, 2005). Demokratisnya suatu partai politik bila pengambilan keputusan penting (seperti rekrutmen dan seleksi kandidat, seleksi pemimpin dan setting kebijakan partai) melibatkan anggota partai atau lebih luas lagi mampu melibatkan kelompok pendukung partai (Scarrow, 2005: 5-11). Penggunaan teori ini dipandang cukup mapan untuk menuntun peneliti dalam melakukan penyelidikan yang berkaitan dengan proses-proses yang terjadi dalam aktivitas internal partai politik apakah terlaksana secara demokratis atau tidak. Teori ini dikatakan mapan karena menempatkan nilai inklusifitas di internal partai dalam pengambilan keputusankeputusan penting partai seperti proses rekrutmen legislatif, rekrutmen pemimpin partai dan arah kebijakan partai yang keseluruhan dari penekanan perhatian
Scarrow (2005) diperlukan dalam menyelesaikan masalah-masalah di internal partai politik Indonesia saat ini. Sementara itu konsep modernisasi partai politik yang akan digunakan sebagai acuan dalam penelitian ini ialah konsep modernisasi partai politik yang dikemukakan oleh Hofmeister and Grabow (2011).

\section{Model Hofmeister dan Grabow}

Hofmeister and Grabow (2011: 2655) memberikan 10 indikator untuk membentuk manajemen partai politik modern yaitu : (1) keanggotaan dan organisasi. (2) para anggota partai. (3) rekrutmen anggota baru. (4) Pendidikan dan pelatihan anggota partai. (5)Program Partai Politik. (6)Komunikasi internal dan eksternal. (7) Demokrasi internal partai. (8)Konflik partai dan resolusi konflik. (9) Kuota untuk perempuan dan minoritas. (10) Pembiayaan Partai. konsep Hofmeister and Grabow (2011) dinilai relevan untuk diterima sebagai representasi konsep moderniasai partai politik yang layak untuk diterapkan di Indonesia dengan alasan 1). Konsep yang dijabarkan dalam indikatorindikator yang disinggung oleh Hofmeister and Grabow (2011) menjadi perhatian yang sama dalam masalah di internal kelembagaan partai politik di Indonesia, 2) Indonesia merupakan negara demokrasi modern, dan 3) terdapat partai politik di Indonesia yang telah mewacanakan melakukan modernisasi partai politik mereka. Keinginan mendemokratiskan partai politik melalui konsep modernisasi sesungguhnya telah diwacanakan oleh beberapa partai politik di Indonesia diantaranya Partai Demokrasi Indonesia Perjuangan (PDIP) (Lihat http://nasional.sindonews.com), dan pada partai lainnya konsep modernisasi partai di suarakan oleh salah satu calon ketua umum partai Golkar (http://news.liputan6.com/read/2476232/bak al-caketum-golkar-ini-bakal-modernisasipartai-politik, akses 12 Agustus 2016). 


\section{METODE PENELITIAN}

Penelitian ini menggunakan pendekatan kualitatif dengan metode deskriptif. Karena studi ini membedah persoalan dengan menggunakan teori maka jenis penelitian kualitatif ini berjenis Grounded Theory. Penetapan jenis penelitian Grounded Theory dikarenakan studi ini akan menjawab suatu fenomena dengan menggunakan teori sebagai alat untuk menganalisis dan mendapatkan jawaban terhadap masalah yang dikaji. Kajian ini menggunakan studi pustaka dan studi dokumentasi untuk memperkaya basis argumentasi dan data. Sumber data diperoleh melalui literatur buku dan dokumen-dokumen secara tertulis yang relevan terhadap kajian ini.

\section{HASIL DAN PEMBAHASAN \\ Manajemen Partai Politik Modern}

Kata kunci yang diberikan Scarrow (2005: 5-11) dalam teorinya mengenai partai politik yang demokratis menekankan perhatian terhadap keterlibatan lebih luas lagi bagi pihak internal dan ekstrnal partai dalam setiap proses di internal kelembagaan partai. keterlibatan yang lebih luas berarti menyediakan ruang partisipasi bagi keanggotaan partai dan publik luas yang diatur melalui peraturan partai. Dengan partisipasi yang lebih luas maka wujud keterbukaan dan pertanggungjawaban partai terhadap publik akan dapat dengan cepat di "terima" publik. Sehingga prinsip demokrasi yang di pahami publik dalam konsep Good Governance pada konteks hubungan masyarakat dengan negara juga dirasakan oleh publik terimplementasi dalam arena kelembagaan partai politik.

Harapan publik untuk terwujudnya partai politik yang demokratis telah menjadi perhatian di hampir setiap negara demokrasi bahkan publik yang berada di negara non demokrasi. Untuk dapat mengembangkan "iklim" demokratisasi di kelembagaan partai politik salah satu gagasan yang muncul ialah dengan melakukan manajemen partai politik secara modern. Sebagai bahan referensi kajian Webb (2001: 308-321) melalui karyanya berjudul "Parties and party systems: Modernisation, regulation and diversity" yang mengambil lokasi studi penelitian di Inggris menemukan pembangunan partai politik yang modern dilakukan melalui pembentukan undangundang baru yang memperketat prilaku kelembagaan partai politik agar sejalan dengan prinsip-prinsip demokratis. Pembentukan undang-undang baru tersebut menyentuh 9 aspek yaitu 1) pembentukan komisi pemilu Independen yang memiliki fungsi pengawasan dan investigasi terhadap administrasi pemilu, pendanaan partai, pemberian suara (jajak pendapat/pemilihan), 2) pemberlakuan sistem multi partai dengan syarat terterntu, 3) penerbitan laporan tahunan pendapatan dan pengeluaran keuangan partai politik untuk di audit oleh komisi pemilihan independen. 4).Kontrol keuangan partai politik yang bersumber dari sumbangan (bentuk uang dan properti). 5) Pembatasan jumlah pengeluaran kampanye kandidat. 6) Pembatasan jumlah sumbangan (uang dan properti) dari pihak ketiga, 7) pengaturan dan kontrol pelaksanaan penggunaan hak suara di pemilihan, 8) pembatasan dana kampanye bagi calon legislatif, 9) pengaturan sumbangan politik yang bersumber dari perusahaan harus melalui persetujuan pemegang saham (Webb, 2001: 312-315).

Studi Webb (2001) telah memberikan konsep transparansi, akuntabilitas dan pendanaan partai yang keseluruhan ini mendekati pada prinsip-prinsip yang berlaku umum dalam negara demokrasi. Sementara itu konsep demokratisasi partai politik melalui pendekatan kelembagaan partai yang dikemukakan Hofmeister and Grabow (2011: 26-55) memberikan konsep manajemen partai politik modern untuk melakukan demokratisasi kelembagaan partai politik. Hofmeister and Grabow (2011: 26-55) memberikan 10 indikator yang harus "disentuh" untuk mencapai manajemen partai politik modern yaitu: (1) keanggotaan dan organisasi. (2) para anggota partai. (3) rekrutmen anggota baru. (4) Pendidikan dan pelatihan anggota partai. (5) Program Partai Politik. (6) Komunikasi internal dan eksternal. (7) Demokrasi 
internal partai. (8) Konflik partai dan resolusi konflik. (9) Kuota untuk perempuan dan minoritas. (10) Pembiayaan Partai. Untuk dapat memeriksa sejauh mana konsep manajemen partai politik modern Hofmeister and Grabow (2011) sejalan dengan manajemen partai politik di Indonesia maka akan ditelaah Peraturan Perundang-undangan yang berlaku dan berkaitan.

\section{Manajemen Partai Politik Dalam Perspektif Regulasi di Indonesia}

Dalam struktur formal perundnagundangan di Indonesia pengaturan mengenai partai politik diatur dalam Undang-Undang (UU) nomor 2 tahun 2008 tentang Partai Politik, namun sebagian pasal dari UU tersebut diubah melalui UU nomor 2 tahun 2011 tentang perubahan atas UndangUndang nomor 2 tahun 2008 tentang Partai Politik. Undang-Undang ini menyentuh pengaturan terhadap manajemen kelembagaan partai politik diantaranya menyangkut organisasi, keuangan partai, penyelesaian konflik partai, dan secara lebih rinci akan dijelaskan pada tabel di bawah ini dengan membandingkan dengan konsep Hofmeister and Grabow (2011) mengenai manajemen partai politik modern.

Tabel: Indikator Konsep Manajemen Partai Politik Modern

\begin{tabular}{|c|c|c|c|}
\hline $\begin{array}{l}\mathrm{N} \\
\mathrm{O}\end{array}$ & $\begin{array}{c}\text { Konsep } \\
\text { Manajemen } \\
\text { Partai } \\
\text { Politik } \\
\text { Modern. } \\
\text { (Hofmeiste } \\
\text { r dan } \\
\text { Grabow, } \\
\text { 2011) }\end{array}$ & $\begin{array}{c}\text { Undang-Undang } \\
\text { No. } 2 \text { tahun } 2011 \\
\text { tentang } \\
\text { perubahan atas } \\
\text { Undang-Undang } \\
\text { nomor } 2 \text { tahun } \\
2008 \text { tentang } \\
\text { Partai Politik }\end{array}$ & Keterangan \\
\hline 1 & $\begin{array}{l}\text { Keanggota } \\
\text { an dan } \\
\text { organisasi }\end{array}$ & $\begin{array}{l}\sqrt{ } \text { Pasal } 14,15, \\
16,17,18,19, \\
20, \text { sampai Pasal } \\
26\end{array}$ & $\begin{array}{l}\text { Diatur } \\
\text { lebih lanjut } \\
\text { dalam } \\
\text { peraturan } \\
\text { internal } \\
\text { partai }\end{array}$ \\
\hline 2 & $\begin{array}{l}\text { para } \\
\text { anggota } \\
\text { partai }\end{array}$ & $\sqrt{\text { Pasal } 14}$ & $\begin{array}{l}\text { Diatur } \\
\text { lebih lanjut } \\
\text { dalam } \\
\text { peraturan } \\
\text { internal } \\
\text { partai }\end{array}$ \\
\hline
\end{tabular}

\begin{tabular}{|c|c|c|c|}
\hline 3 & $\begin{array}{l}\text { rekrutmen } \\
\text { anggota } \\
\text { baru }\end{array}$ & $\sqrt{\text { Pasal } 11 \text { dan } 29}$ & $\begin{array}{l}\text { Diatur } \\
\text { lebih lanjut } \\
\text { dalam } \\
\text { peraturan } \\
\text { internal } \\
\text { partai }\end{array}$ \\
\hline 4 & $\begin{array}{l}\text { Pendidikan } \\
\text { dan } \\
\text { pelatihan } \\
\text { anggota } \\
\text { partai }\end{array}$ & $\sqrt{\text { Pasal } 2 \text { dan } 31}$ & $\begin{array}{l}\text { Diatur } \\
\text { lebih lanjut } \\
\text { dalam } \\
\text { peraturan } \\
\text { internal } \\
\text { partai }\end{array}$ \\
\hline 5 & $\begin{array}{l}\text { Program } \\
\text { Partai } \\
\text { Politik. }\end{array}$ & $\sqrt{\text { Pasal } 10}$ & $\begin{array}{l}\text { Diatur } \\
\text { lebih lanjut } \\
\text { dalam } \\
\text { peraturan } \\
\text { internal } \\
\text { partai }\end{array}$ \\
\hline 6 & $\begin{array}{l}\text { Komunikas } \\
\text { i internal } \\
\text { dan } \\
\text { eksternal }\end{array}$ & $\sqrt{\text { Pasal } 11 \text { dan } 31}$ & $\begin{array}{l}\text { Diatur } \\
\text { lebih lanjut } \\
\text { dalam } \\
\text { peraturan } \\
\text { internal } \\
\text { partai }\end{array}$ \\
\hline 7 & $\begin{array}{l}\text { Demokrasi } \\
\text { internal } \\
\text { partai }\end{array}$ & $\sqrt{\text { Pasal } 27 \text { dan } 28}$ & $\begin{array}{l}\text { Diatur } \\
\text { lebih lanjut } \\
\text { dalam } \\
\text { peraturan } \\
\text { internal } \\
\text { partai }\end{array}$ \\
\hline 8 & $\begin{array}{l}\text { Konflik } \\
\text { partai dan } \\
\text { resolusi } \\
\text { konflik }\end{array}$ & $\sqrt{ }$ Pasal 32 dan 33 & $\begin{array}{l}\text { Diatur } \\
\text { lebih lanjut } \\
\text { dalam } \\
\text { peraturan } \\
\text { internal } \\
\text { partai }\end{array}$ \\
\hline 9 & $\begin{array}{l}\text { Kuota } \\
\text { untuk } \\
\text { perempuan } \\
\text { dan } \\
\text { minoritas }\end{array}$ & $\sqrt{\text { Pasal } 2 \text { dan } 20}$ & $\begin{array}{l}\text { Hanya } \\
\text { kuota } \\
\text { perempuan }\end{array}$ \\
\hline $\begin{array}{l}1 \\
0\end{array}$ & $\begin{array}{l}\text { Pembiayaa } \\
\text { n Partai }\end{array}$ & $\begin{array}{l}\sqrt{ } \text { Pasal } 34 \\
\text { sampai Pasal } 39\end{array}$ & $\begin{array}{l}\text { Diatur } \\
\text { lebih lanjut } \\
\text { dalam } \\
\text { peraturan } \\
\text { internal } \\
\text { partai }\end{array}$ \\
\hline
\end{tabular}

Dari telaah Undang-Undang nomor 2 tahun 2011 tentang perubahan atas UndangUndang nomor 2 tahun 2008 tentang Partai Politik dan dikaitkan pada konsep manajemen partai politik modern yang dikemukakan Hofmeister dan Grabow (2011) ditemukan hanya kuota minoritas tidak terakomodasi sementara itu indikator lainnya terakomodasi dalam UU nomor 2 tahun 2011. Selain itu peran dari peraturan 
GOVERNANCE

Jurnal Ilmiah Kajian Politik Lokal dan Pembangunan
ISSN: 2406-8721 (Print)

ISSN: 2406-8985 (Online) internal partai dalam bentuk anggaran dasar (AD) dan anggaran rumah tangga (ART) turut memberikan rincian mengenai penjelasan pada tiap-tiap indikator yang disebut Hofmeister dan Grabow (2011).

Dalam tataran hukum formal pengaturan mengenai partai politik di Indonesia secara universal telah sesuai dengan konsep Hofmeister dan Grabow (2011) mengenai manajemen partai politik modern sementara dalam tataran implementasi menjadi domain arena dari setiap partai politik untuk merealisasi indikator-indikator tersebut. Dengan menggunakan data kajian empiris dari Haris, dkk (2004); Febriani (2011); Saputra (2012) rekrutmen calon legislatif yang dilaksanakan beberapa partai politik menjelang Pemilu berlangsung secara tertutup dan partai mendapati kesulitan memenuhi 30 persen kuota perempuan untuk calon legislatif. Kajian empiris ini sebagai contoh kajian yang mengingatkan bahwa ada persoalan penting mengenai demokratisasi di internal partai politik yang mengisyaratkan bahwa kemajuan demokratisasi di kelembagaan partai politik hanya dapat tercapai melalui komitmen dari partai politik itu sendiri.

\section{PENUTUP}

\section{Kesimpulan}

Argumentasi berbasis teori dan kajian empiris telah menyajikan konsep kuat mengenai manajemen partai politik modern yang dalam studi ini menggunakan konsep Hofmeister dan Grabow (2011). Dalam konteks peraturan perundang-undangan di Indonesia sebagai acuan hukum formal melalui telaah Undang-Undang (UU) nomor 2 tahun 2011 tentang perubahan atas Undang-Undang nomor 2 tahun 2008 tentang Partai Politik disimpulkan bahwa konsep Hofmeister dan Grabow (2011) mengenai manajemen partai politik modern secara universal terakomodasi di dalam UU nomor 2 tahun 2011 tentang perubahan atas UU nomor 2 tahun 2008 tentang Partai Politik sehingga dapat dikatakan UU tentang partai politik yang berlaku di Indonesia telah berdiri pada posisi menempatkan partai politik di Indonesia sebagai partai politik modern karena secara universal prinsip-prinsip manajemen partai politik modern telah diatur dalam UndangUndang (UU) nomor 2 tahun 2011 tentang perubahan atas Undang-Undang nomor 2 tahun 2008 tentang Partai Politik. Dengan demikian partai politik memiliki peran besar untuk mengimplementasikan UU tersebut di dalam peraturan internal partai hingga pada konteks pelaksanaan dari peraturan partai sehingga publik dapat melihat manajemen partai politik modern berkontribusi terhadap penguatan demokratisasi di kelembagaan partai politik.

\section{DAFTAR PUSTAKA}

Budi, A. (2013). Membongkar Veto Player dalam Politik Kepartaian Indonesia Menuju Pemilu 2014. Jurnal Ilmu Sosial Dan Ilmu Politik, 17(1), 51-66.

Febriani, 2011. Pola Rekrutmen Caleg Perempuan Oleh Partai Politik Pada Pemilu Legislatif Periode 2009-2014 Kabupaten Pesisir Selatan. Skripsi. FISIP : Universitas Andalas.

Haris, Syamsuddin (Ed), Pemilu Langsung di Tengah Oligarki Partai: Proses Nominasi dan Seleksi Calon Legislatif Pemilu 2004, Jakarta: Gramedia, 2005.

He, M. (2004). Functions of Political Parties in Modern Democratic Elections. University of Colorado.

Hofmeister, W., \& Grabow, K. (2011). Political Parties: Functions and Organisation in Democratic Societies. Singapore: Konrad Adenauer Stiftung.

Menes, J. R. (1997). Modernization and Political Cleavages in Open Party System. Sources of Medium Run Instability in Non Consolidated Democracies: The Case of Spain. Dissertation. Northwestern University.

Rahmadania, F. (2014). Rekrutmen Calon Legislatif Pada Pemilu 2014 (Studi Kasus Mengenai Rekrutmen Politik PPP di Dapil I dan V di Kabupaten Sampang, Jawa Timur). Jurnal Politik Muda, 3(1).

Saputra, W. (2012). Pola Rekrutmen Partai Politik (Studi Dewan Pimpinan Cabang (DPC) Partai Demokrat Dalam Menetapkan Caleg Pada Pemilu Legislatif 2009 Di Kabupaten Agam). Skripsi. Universitas Adalas. 
Scarrow, S. (2005). Political parties and democracy in theoretical and practical perspectives: Implementing Intra-Party Democracy. Washington, DC: National Democratic Institute for International Affairs (NDI).

Slater, D. (2004). Indonesia's Accuntability Trap: Party Cartels and Presidential Power After Democratic Transition. Indonesia, 78(Oktober), 61-92. Retrieved from

http://cip.cornell.edu/seap.indo/11081406 58

Webb, P. (2001). Parties and party systems: Modernisation, regulation and diversity. Parliamentary Affairs, 54(2), 308-321. http://doi.org/10.1093/parlij/54.2.308. 